Review

International Journal of Medical Sciences

ISSN 1449-1907 www.medsci.org 2007 4(3):174-178

(C) Ivyspring International Publisher. All rights reserved

\title{
Evidence-Based Dentistry: What's New?
}

\section{A. Ballini 1,2, S. Capodiferro 2, M. Toia ${ }^{3}$, S. Cantore 2, G. Favia 2, G. De Frenza 2, F.R. Grassi ${ }^{2}$}

1. Department of Internal Medicine and Public Health, Division of Medical Genetics, University of Bari, Bari, Italy

2. Department of Odontostomatology and Surgery, University of Bari, Bari, Italy

3. Department of Oral Surgery, ICP - University of Milan, Milan, Italy

Correspondence to: Prof. Felice Roberto Grassi, MD, DMD, PhD, Department of Odontostomatology and Surgery, University of Bari, P.zza G. Cesare 11, 70124 Bari - Italy, Phone: +39 0805594242 , Fax: +39 0805478043 E-mail: robertograssi@doc.uniba.it

Received: 2007.04.18; Accepted: 2007.06.01; Published: 2007.06.06

The importance of evidence for every branch of medicine in teaching in order to orient the practitioners among the great amount of most actual scientific information's, and to support clinical decisions, is well established in health care, including dentistry.

The practice of evidence-based medicine is a process of lifelong, self-directed, problem-based learning which leads to the need for clinically important information about diagnosis, prognosis, therapy and other clinical and health care issues. Nowadays the practice of dentistry is becoming more complex and challenging because of the continually changing in dental materials and equipments, an increasingly litigious society, an increase in the emphasis of continuing professional development, the information explosion and the consumer movement associated with advances on the Internet.

The need for reliable information and the electronic revolution have come together to allow the "paradigm shift" towards evidence-based health care. Recent years have seen an increase in the importance of evidence-based dentistry, aiming to reduce to the maximum the gap between clinical research and real world dental practice. Aim of evidence-based practice is the systematic literature review, which synthesizes the best evidences and provides the basis for clinical practice guidelines. These practice guidelines give a brief review of what evidence-based dentistry is and how to use it.

Key words: dentistry; evidence-based medicine; dental care/standards

\section{Evidence-Based Dentistry}

"What are we to do when the irresistible force of the need to offer clinical advice meets with the immovable object of flawed evidence? All we can do is our best: give the advice, but alert the advisees to the flaws in the evidence on which it is based".

The ancestor of this set of pages was created by Dave Sackett and colleagues [1] who generated "levels of evidence" for ranking the validity of evidence about the value of preventive manoeuvres, and then tied them as "grades of recommendations".

Evidence-based practice has been defined as the practice of dentistry that integrates the best available evidences with clinical experience and what a patient prefer in making clinical decisions.

To do it successfully, certain skills need to be obliviously acquired, being the intention of evidence-based dentistry the providing better information for the clinician, improved treatment for the patient, and consequently an increased standing of the profession [2].

The use of evidence-based dentistry may help in the reducing the variations of patient care and outcomes that appears to be associated with four factors: 1 . the quality of science underlying clinical care, 2 . the quality in making clinical decisions, 3 . the variations of the level of clinical skill, 4 . the large and increasing volume of literature [3].

Evidence-based dentistry has two main goals: best evidence/research, and the transfer of this in practical use. This involves four basic phases: Asking evidence-based questions (framing an answerable question from a clinical problem); Searching for the best evidence; Reviewing and critically appraising the evidence; Applying this information in a way to help the clinical practice $[1,4]$.

Carr and McGivney [5] have suggested an additional phase that is the evaluation of performance of the techniques, procedures or materials.

In such way it's possible to obtain advantages in structuring the way to consider clinical problems. This way to approach the clinical decisions becomes increasingly important as in the last 50 years many new materials, drugs, interventions and products have appeared together with new clinical techniques and methods to use these materials. This raises the following questions: how is the average practitioner expected to remain currently updated with these developments, materials and products work as claimed, and which claims will result in improvements for both patient and dentist?

Unfortunately, many questions exist in the obtaining evidence; first of all, it is generally accepted that good clinical researches helpful to obtain evidence 
[6] are above all the prospective randomised controlled trials which are very slow to carry out; besides, another adjunctive problem is the limited space available in journals which makes the time for publication often very long.

In addition, few clinical situations in dentistry are life-threatening, so the impetus to perform rigorous clinical research to compare efficacy of dental therapies may not seem as important as in some other medical therapies [7]. To overcome this, many companies publish pseudo-scientific papers in order to provide some not specific form of evidence only to support their products.

Besides, nowadays also patients ask more frequently several options of treatment [8] because they are generally informed by notice available by internet world. $[9,10]$ and also society has become more litigious [11].

The use of evidence-based dentistry provides a solution to these problems for the dentist. The use of an evidence-based approach can surely help clinicians who want to stay abreast of changes in their areas of health care by assisting them with the selection of relevant articles, and will aid them to efficiently extract and apply the information's. [12] Computerised medical databases, such as Medline, Pub Med and The Cochrane Collaboration, have made easier both the distribution and the access to information. [13] These can be found here at the NZDA website.

Today, other strategies available to help the dentist keep abreast with the current information are: [12] Professional journals, many also available on-line; Web-based continuing education programs; Books, audio and video tapes (which often not suggest the most recent information and may suffer from the personal point of view of the author(s); Professional and university continuing education meetings which should give the possibility to interact with the author of a new evidence; Study clubs composed by colleagues.

It is generally accepted that systematic reviews and randomised controlled trials represent the best levels of evidence, whereas case reports and expert opinions are the lowest; with regard to diagnosis, prognosis or causation, cohort studies or case control studies are surely more appropriate, remaining clearly defined in any of these study inclusion and exclusion criteria adopted $[14,15]$

Nowadays, the majority of today's clinical practice is based on the last three types of study. However, these kinds of study meet the criteria to be considered as evidence-based studies? The questions are: how was the study carried out?; was there an independent, blind comparison with a control?, was allocation of patients to study groups random?; how do the aims and study design contribute to the understanding of a clinical condition or decision?; were the methods for performing the test described in sufficient detail to permit replication?; are the results likely to be valid?; what are the results of the study, and will they help provide better patient treatment?; were both statistical and clinical significance considered?; how does the subject population of the study compare with the patients that make up clinical practice?; are the findings applicable, relevant and feasible in clinical practice?; what are the risks and will the patients be better off? $[1,16]$

Finally, it should be consider whether the treatment or outcome has some relevance to clinical practice in order to give some benefit to the society.

In the evidence based medicine process, several steps should be performed starting from a clinical problem arising out of the care of patient which creates a well built clinical question; subsequently, appropriate resources should be select and the search conduct in order to appraise the evidence for its validity and applicability in the clinical practice integrating the new evidence with clinical expertise and patient preferences; the last step of this process should be a self-evaluation of the performance with the patient.

With a strict regard to dentistry, it should be underlined that several that many aspects have been introduced without randomised controlled trials, and dental implants are a good example; in fact, many study on implantology are based on a large number of clinical cases and prolonged follow-up but nonetheless uncontrolled. [17] The main reason is that such studies are expensive to conduct, difficult to blind, and often require limited inclusion criteria, or are ethically impossible to undertake. [18] Only by using a hierarchical analysis of the literature, clinicians can make decisions based on the best available evidence.

Evidence-based dentistry is the use of current best evidence in making decisions about the care of individual patients. Carrying out evidence-based dentistry requires that the practitioner question and think about what they are doing, particularly in this era of expectation that dentists will keep abreast of new techniques and developments. Information needs to be assessed, and its validity determined. To properly practice evidence-based dentistry means that time must be spent searching and assessing the literature, and information from any source should be questioned. By formulating a clinical question, carrying out an efficient literature search, evaluating the literature, and when appropriate, applying it to patient care, dentists can meet the challenges of continuing to provide quality care in a rapidly changing environment. Additional benefits are that it makes it easier to justify treatment decisions, especially when there is a complaint or a dento-legal issue.

\section{Conflict of interest}

The authors have declared that no conflict of interest exists.

\section{References}

1. Sackett DL, Rosenberg WM, Gray JA, Haynes RB and Richardson WS. Evidence based medicine: what it is and what it isn't. British Medical Journal 1996; 312: 71-72.

2. Gianelly AA. Evidence-based treatment strategies: an ambition for the future. American Journal of Orthodontics and 
Dentofacial Orthopedics, 2000; 117: 543-544.

3. Niederman $R$, Chen L, Murzyn L and Conway S. Benchmarking the dental randomised controlled literature on MEDLINE. Evidence-Based Dentistry, 2002; 3: 5-9.

4. Lawrence A. Welcome to evidence-based dentistry. Evidence-Based Dentistry, 1998; 1: 2-3.

5. Carr $\mathrm{AB}$ and McGivney GP. Users' guides to the dental literature: how to get started. Journal of Prosthetic Dentistry, 2000; 83: 13-20.

6. Sackett DL. How to read clinical journals: V: To distinguish useful from useless or even harmful therapy. Canadian Medical Association Journal, 1981; 124: 1156-1162.

7. Jacob RF and Carr AB. Hierarchy of research design used to categorize the "strength of evidence" in answering clinical dental questions. Journal of Prosthetic Dentistry, 2000; 83: 137-152.

8. Neilson P. Evidence-based dentistry: what is it, and what does it have to do with practice? It works in my hands. Why isn't that good enough? Quintessence International, 1998; 29: 799-802.

9. Freydberg B. Get with the Net. Journal of the American Dental Association, 1997; 128: 1654-1656.

10. Niederman R. Evidence-based esthetic dentistry. Journal of Esthetic Dentistry, 1998; 10: 229-234.
11. Cannavina CD, Cannavina $G$ and Walsh TF. Effects of evidence-based treatment and consent on professional autonomy. British Dental Journal, 2000; 188: 302-306.

12. Dodson TB. Evidence-based medicine: its role in the modern practice and teaching of dentistry. Oral Surgery Oral Medicine Oral Pathology Oral Radiology \& Endodontics, 1997; 83: 192-197.

13. Greenhalgh T. How to read a paper. The Medline database. British Medical Journal, 1997; 315: 180-183.

14. Bader J, Ismali A and Clarkson J. Evidence-based dentistry and the dental research community. Journal of Dental Research, 1999; 78: 1480-1483.

15. Sutherland SE. Evidence-based dentistry: Part IV. Research design and levels of evidence. Journal of the Canadian Dental Association, 2001; 67: 375-378.

16. Haynes RB. Transferring evidence from research into practice: 1. The role of clinical care research evidence in clinical decisions. ACP Journal Club, 1996; 125: 14-16.

17. Anderson JD. Need for evidence-based practice in prosthodontics. Journal of Prosthetic Dentistry 83: 58-65, 2000.

18. Chalmers TC. Bias in treatment assignment in controlled clinical trials. New England Journal of Medicine, 1983; 309: 1358-1361.

\section{Tables}

Table 1. Evidence-based Medicine/Dentistry: Levels of Evidence

\begin{tabular}{|c|c|c|c|c|c|}
\hline Level & $\begin{array}{c}\text { Therapy/Prevention, } \\
\text { Aetiology/Harm }\end{array}$ & Prognosis & Diagnosis & $\begin{array}{c}\text { Differential } \\
\text { diagnosis/symptom } \\
\text { prevalence study }\end{array}$ & $\begin{array}{c}\text { Economic and decision } \\
\text { analyses }\end{array}$ \\
\hline $1 \mathrm{a}$ & $\begin{array}{c}\text { SR (with } \\
\text { homogeneity*) of RCTs }\end{array}$ & $\begin{array}{c}\text { SR (with } \\
\text { homogeneity*) of } \\
\text { inception cohort } \\
\text { studies; CDR† } \\
\text { validated in different } \\
\text { populations }\end{array}$ & $\begin{array}{c}\text { SR (with } \\
\text { homogeneity*) of Level } \\
1 \text { diagnostic studies; } \\
\text { CDR† with } 1 \text { b studies } \\
\text { from different clinical } \\
\text { centres }\end{array}$ & $\begin{array}{c}\text { SR (with } \\
\text { homogeneity*) of } \\
\text { prospective cohort } \\
\text { studies }\end{array}$ & $\begin{array}{c}\text { SR (with } \\
\text { homogeneity*) of Level }^{*} \\
1 \text { economic studies }\end{array}$ \\
\hline $1 b$ & $\begin{array}{l}\text { Individual RCT (with } \\
\text { narrow Confidence } \\
\text { Interval } \neq \text { ) }\end{array}$ & $\begin{array}{l}\text { Individual inception } \\
\text { cohort study with } \geq \\
80 \% \text { follow-up; CDR } † \\
\text { validated in a single } \\
\text { population }\end{array}$ & $\begin{array}{l}\text { Validating** cohort } \\
\text { study with good }+\dagger \dagger \\
\text { reference standards; or } \\
\text { CDR† tested within one } \\
\text { clinical centre }\end{array}$ & $\begin{array}{l}\text { Prospective cohort } \\
\text { study with good } \\
\text { follow-up }\end{array}$ & $\begin{array}{l}\text { Analysis based on } \\
\text { clinically sensible costs } \\
\text { or alternatives; } \\
\text { systematic review(s) of } \\
\text { the evidence; and } \\
\text { including multi-way } \\
\text { sensitivity analyses }\end{array}$ \\
\hline 1c & All or none§ & All or none case-series & $\begin{array}{c}\text { Absolute SpPins and } \\
\text { SnNouts } \dagger \dagger\end{array}$ & All or none case-series & $\begin{array}{l}\text { Absolute better-value } \\
\text { or worse-value } \\
\text { analyses } † \dagger \dagger \dagger\end{array}$ \\
\hline $2 a$ & $\begin{array}{c}\text { SR (with } \\
\text { homogeneity* }^{*} \text { of } \\
\text { cohort studies }\end{array}$ & $\begin{array}{l}\text { SR (with } \\
\text { homogeneity*) of either } \\
\text { retrospective cohort } \\
\text { studies or untreated } \\
\text { control groups in RCTs }\end{array}$ & $\begin{array}{c}\text { SR (with } \\
\text { homogeneity*) of Level } \\
>2 \text { diagnostic studies }\end{array}$ & $\begin{array}{c}\text { SR }(\text { with } \\
\text { homogeneity*) of } 2 b \\
\text { and better studies }\end{array}$ & $\begin{array}{c}\text { SR (with } \\
\text { homogeneity*) of Level } \\
>2 \text { economic studies }\end{array}$ \\
\hline $2 b$ & $\begin{array}{l}\text { Individual cohort study } \\
\text { (including low quality } \\
\text { RCT; e.g., }<80 \% \\
\text { follow-up) }\end{array}$ & $\begin{array}{l}\text { Retrospective cohort } \\
\text { study or follow-up of } \\
\text { untreated control } \\
\text { patients in an RCT; } \\
\text { Derivation of CDR† or } \\
\text { validated on } \\
\text { split-sample§§§ only }\end{array}$ & $\begin{array}{l}\text { Exploratory** cohort } \\
\text { study with good ††† } \\
\text { reference standards; } \\
\text { CDR† after derivation, } \\
\text { or validated only on } \\
\text { split-sample§§§ or } \\
\text { databases }\end{array}$ & $\begin{array}{l}\text { Retrospective cohort } \\
\text { study, or poor } \\
\text { follow-up }\end{array}$ & $\begin{array}{l}\text { Analysis based on } \\
\text { clinically sensible costs } \\
\text { or alternatives; limited } \\
\text { review(s) of the } \\
\text { evidence, or single } \\
\text { studies; and including } \\
\text { multi-way sensitivity } \\
\text { analyses }\end{array}$ \\
\hline $2 \mathrm{c}$ & $\begin{array}{l}\text { "Outcomes" Research; } \\
\text { Ecological studies }\end{array}$ & "Outcomes" Research & & Ecological studies & $\begin{array}{l}\text { Audit or outcomes } \\
\text { research }\end{array}$ \\
\hline $3 a$ & $\begin{array}{c}\text { SR }(\text { with } \\
\text { homogeneity*) of } \\
\text { case-control studies }\end{array}$ & & $\begin{array}{c}\text { SR (with } \\
\text { homogeneity*) of } 3 b \\
\text { and better studies }\end{array}$ & $\begin{array}{c}\text { SR (with } \\
\text { homogeneity*) of } 3 b \\
\text { and better studies }\end{array}$ & $\begin{array}{c}\text { SR (with } \\
\text { homogeneity*) of } 3 b \\
\text { and better studies }\end{array}$ \\
\hline $3 b$ & $\begin{array}{c}\text { Individual } \\
\text { Case-Control Study }\end{array}$ & & $\begin{array}{l}\text { Non-consecutive study; } \\
\text { or without consistently } \\
\text { applied reference } \\
\text { standards }\end{array}$ & $\begin{array}{l}\text { Non-consecutive } \\
\text { cohort study, or very } \\
\text { limited population }\end{array}$ & $\begin{array}{l}\text { Analysis based on } \\
\text { limited alternatives or } \\
\text { costs, poor quality } \\
\text { estimates of data, but } \\
\text { including sensitivity } \\
\text { analyses incorporating } \\
\text { clinically sensible } \\
\text { variations. }\end{array}$ \\
\hline 4 & $\begin{array}{l}\text { Case-series (and poor } \\
\text { quality cohort and } \\
\text { case-control studies§§ ) }\end{array}$ & $\begin{array}{l}\text { Case-series (and poor } \\
\text { quality prognostic } \\
\text { cohort studies }^{* * *} \text { ) }\end{array}$ & $\begin{array}{l}\text { Case-control study, } \\
\text { poor or } \\
\text { non-independent }\end{array}$ & $\begin{array}{c}\text { Case-series or } \\
\text { superseded reference } \\
\text { standards }\end{array}$ & $\begin{array}{l}\text { Analysis with no } \\
\text { sensitivity analysis }\end{array}$ \\
\hline
\end{tabular}




\begin{tabular}{|c|c|c|c|c|c|}
\hline & & & reference standard & & \\
\hline 5 & $\begin{array}{l}\text { Expert opinion without } \\
\text { explicit critical } \\
\text { appraisal, or based on } \\
\text { physiology, bench } \\
\text { research or "first } \\
\text { principles" }\end{array}$ & $\begin{array}{l}\text { Expert opinion without } \\
\text { explicit critical } \\
\text { appraisal, or based on } \\
\text { physiology, bench } \\
\text { research or "first } \\
\text { principles" }\end{array}$ & $\begin{array}{l}\text { Expert opinion without } \\
\text { explicit critical } \\
\text { appraisal, or based on } \\
\text { physiology, bench } \\
\text { research or "first } \\
\text { principles" }\end{array}$ & $\begin{array}{l}\text { Expert opinion without } \\
\text { explicit critical } \\
\text { appraisal, or based on } \\
\text { physiology, bench } \\
\text { research or "first } \\
\text { principles" }\end{array}$ & $\begin{array}{l}\text { Expert opinion without } \\
\text { explicit critical } \\
\text { appraisal, or based on } \\
\text { economic theory or } \\
\text { "first principles" }\end{array}$ \\
\hline
\end{tabular}

Users can add a minus-sign "-" to denote the level of that fails to provide a conclusive answer because of: EITHER a single result with a wide Confidence Interval (such that, for example, an ARR (Absolute Risk Reduction is the difference in risk between the control group (X) and the treatment group $(Y)$ ) in an RCT is not statistically significant but whose confidence intervals fail to exclude clinically important benefit or harm), OR a Systematic Review with troublesome (and statistically significant) heterogeneity. Such evidence is inconclusive, and therefore can only generate Grade D recommendations.

* By homogeneity we mean a systematic review that is free of worrisome variations (heterogeneity) in the directions and degrees of results between individual studies. Not all systematic reviews with statistically significant heterogeneity need be worrisome, and not all worrisome heterogeneity need be statistically significant. As noted above, studies displaying worrisome heterogeneity should be tagged with a "-" at the end of their designated level.

$\dagger \quad$ Clinical Decision Rule. (These are algorithms or scoring systems which lead to a prognostic estimation or a diagnostic category. )

$\ddagger \quad$ See note \#2 for advice on how to understand, rate and use trials or other studies with wide confidence intervals.

$\S \quad$ Met when all patients died before the Rx became available, but some now survive on it; or when some patients died before the Rx became available, but none now die on it.

$\S \S \quad$ By poor quality cohort study we mean one that failed to clearly define comparison groups and/or failed to measure exposures and outcomes in the same (preferably blinded), objective way in both exposed and non-exposed individuals and/or failed to identify or appropriately control known confounders and/or failed to carry out a sufficiently long and complete follow-up of patients. By poor quality case-control study we mean one that failed to clearly define comparison groups and/or failed to measure exposures and outcomes in the same (preferably blinded), objective way in both cases and controls and/or failed to identify or appropriately control known confounders. $\S \S \S \quad$ Split-sample validation is achieved by collecting all the information in a single tranche, then artificially dividing this into "derivation" and "validation" samples.

†† An "Absolute SpPin" is a diagnostic finding whose Specificity is so high that a Positive result rules-in the diagnosis. An "Absolute SnNout" is a diagnostic finding whose Sensitivity is so high that a Negative result rules-out the diagnosis.

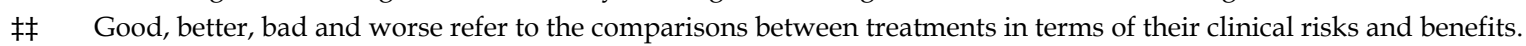

t† Good reference standards are independent of the test, and applied blindly or objectively to applied to all patients. Poor reference standards are haphazardly applied, but still independent of the test. Use of a non-independent reference standard (where the 'test' is included in the 'reference', or where the 'testing' affects the 'reference') implies a level 4 study.

$\uparrow \uparrow \uparrow \dagger$ Better-value treatments are clearly as good but cheaper, or better at the same or reduced cost. Worse-value treatments are as good and more expensive, or worse and the equally or more expensive.

** Validating studies test the quality of a specific diagnostic test, based on prior evidence. An exploratory study collects information and trawls the data (e.g. using a regression analysis) to find which factors are 'significant'.

*** By poor quality prognostic cohort study we mean one in which sampling was biased in favour of patients who already had the target outcome, or the measurement of outcomes was accomplished in $<80 \%$ of study patients, or outcomes were determined in an unblinded, non-objective way, or there was no correction for confounding factors.

**** Good follow-up in a differential diagnosis study is $>80 \%$, with adequate time for alternative diagnoses to emerge (eg 1-6 months acute, 1 - 5 years chronic)

Table 2. Grades of Recommendation

\begin{tabular}{|c|c|}
\hline A & consistent level 1 studies \\
\hline B & consistent level 2 or 3 studies or extrapolations from level 1 studies \\
\hline C & level 4 studies or extrapolations from level 2 or 3 studies \\
\hline D & level 5 evidence or troublingly inconsistent or inconclusive studies of any level \\
\hline
\end{tabular}

"Extrapolations" are where data is used in a situation which has potentially clinical important differences than the original study situation.

Table 3. Evidence-based Medicine/Dentistry Glossary

\begin{tabular}{|c|c|}
\hline Case-controlled study & $\begin{array}{l}\text { involves identifying subjects with a clinical condition (cases) and subjects free from the condition } \\
\text { (controls), and investigating if the two groups have similar or different exposures to risk indicator(s) of } \\
\text { factor(s) associated with the disease }\end{array}$ \\
\hline Case-series & report on a series of patients with an outcome of interest. No control group is involved \\
\hline Cohort study & $\begin{array}{l}\text { involves identifying two groups (cohorts) of subjects, one that did receive the exposure of interest and } \\
\text { another that did not, and following these cohorts forward for the outcome of interest }\end{array}$ \\
\hline Controlled clinical trial & $\begin{array}{c}\text { study that uses the same design features of a randomized controlled clinical trial, but, for reasons beyond } \\
\text { the control of the investigators, the subjects are assigned using a non-random process into control or } \\
\text { experimental groups }\end{array}$ \\
\hline Crossover study design & $\begin{array}{l}\text { administration of two or more experimental therapies, one after the other in a specified or random order, } \\
\text { to the same group of patients }\end{array}$ \\
\hline
\end{tabular}


Int. J. Med. Sci. 2007, 4

\begin{tabular}{|c|c|}
\hline Cross-sectional study & $\begin{array}{c}\text { observation of a defined population at a single point in time or a specified time interval. Exposure and } \\
\text { outcome are measured simultaneously }\end{array}$ \\
\hline Meta-analysis & $\begin{array}{l}\text { review that uses quantitative methods to combine the statistical measures from two or more studies and } \\
\text { generates a weighted average of the effect of an intervention, degree of association between a risk factor } \\
\text { and a disease, or accuracy of a diagnostic test }\end{array}$ \\
\hline $\begin{array}{l}\text { Randomised controlled clinical } \\
\text { trial } \\
\text { (RCT) }\end{array}$ & $\begin{array}{l}\text { study that randomises a group of subjects into an experimental group and a control group. The } \\
\text { experimental group receives the new intervention and the control group receives a placebo or standard } \\
\text { intervention. These groups are followed up for the outcomes of interest }\end{array}$ \\
\hline $\begin{array}{l}\text { Systematic-review } \\
\text { (SR) }\end{array}$ & $\begin{array}{l}\text { a process of systematically locating, appraising and synthesising evidence from scientific studies in order } \\
\text { to obtain a reliable overview. The aim is to ensure a review process that is comprehensive and unbiased. } \\
\text { Findings from systematic reviews may be used for decision-making about research and the provision of } \\
\text { health care }\end{array}$ \\
\hline $\begin{array}{l}\text { Absolute Risk Reduction } \\
\text { (AAR) }\end{array}$ & $\begin{array}{l}\text { is the difference in risk between the control group }(X) \text { and the treatment group }(Y) . \\
\qquad A A R=X-Y\end{array}$ \\
\hline
\end{tabular}

